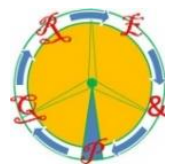

\title{
Numerical analysis of the inlet channel and basin geometries for vortex generation in a gravitational water vortex power plant
}

\author{
Velásquez García L ${ }^{1}$, Rubio-Clemente $\mathrm{A}^{\mathbf{1 , 2}}$, Chica $\mathrm{E}^{1}$ \\ ${ }^{1}$ Departamento de Ingeniería Mecánica, Facultad de Ingeniería, Universidad de Antioquia UdeA, Calle 70, No. 52-21, \\ Medellín, Colombia. \\ ${ }^{2}$ Facultad de Ingeniería, Tecnológico de Antioquia-Institución Universitaria TdeA, Calle 78b, No. 72A-220, Medellín, \\ Colombia.
}

Phone/Fax number: +0057 2195547, e-mail: edwin.chica@udea.edu.co

\begin{abstract}
Recently, the utilization of low-head hydroelectric technologies has received a great attention for the expansion of distributed power systems into isolated regions that are difficult to be connected to the electrical grid, especially in developing countries. The use of gravitational vortex hydropower systems can be a renewable and suitable option to expand electricity access and promote development in these remote regions, which are concomitantly rich in hydric resources, due to this system can operate with low head without the need of a large reservoir and installation area.

In this study, the performance of the inlet channel and basin of a gravitational water vortex turbine was investigated. Two inlet channels and two basin geometries were numerically analysed in Ansys Fluent software. The velocity and vortex height were calculated and compared for each setting. It was found that the inlet channel with conical basin tended to produce more symmetric vortex in comparisons with that generated by the cylindrical geometry. Additionally, the conical basin maximized the flow velocity on the water surface area.
\end{abstract}

Key words. Gravitational vortex, low-head hydropower, CFD, cylindrical and conical basin

\section{Introduction}

Nowadays, one of the main objectives for developing countries is to achieve the diversification of the energy mix and the enhancement of the energy security due to the demand for electricity has been rapidly increasing and it is expected to further rise in the coming years because of population and economic growth [1,2]. Additionally, the sources of power generation of greater current use, especially the energy obtained from fossil fuels, generate detrimental environmental problems. Therefore, the global trend is focused on the de-carbonization and the use of renewable energy, such as solar and wind energy, small hydropower and hydrokinetic system, and ocean, geothermal and biomass power plant, among others, for the production of electricity [1-3]. Indeed, hydroelectric power remains one of the most cost-efficient sources of renewable energy production. The generation cost depends on the efficiency of the technology used [1-5].
In especial, small hydro-energy is more predictable; typically, it has short construction schedules and is easily built when compared to other renewable forms of energy [3-6]. Around the world, a significant source of green energy could be provided by low head hydropower plants using several types of water turbines; however, for ultralow head, the gravitational water vortex turbine (GWVT) should be used [6-9].

GWVT is a low hydraulic head turbine that extracts energy from an artificially induced gravitational water vortex in the basin of cylindrical or conical configuration. The main advantage of this type of system is the generation of electricity from ultra-low hydraulic pressure, along with it is environmental friendly due to larger dams are not necessary and the manufacturing costs are relatively reduced because of its simpler construction and the use of locally available materials. Additionally, when the water passing through the turbine, it is aerated [6-9].

In a GWVT, the potential energy of water is converted into kinetic energy by using a basin or rotation tank that has a circular orifice at its base [7-9]. River water is channelled at the bank of the river and conveyed to basin using an inlet open channel, which is responsible to tangentially direct the water flow into the basin. The water is released through a hole central at the bottom of the tank and is returned to the river. In the basin, a gravitational vortex is generated and the kinetic energy of water is extracted by a vertical-axis turbine in the centre of the vortex, with rotates coaxially with it to harness the kinetic energy. The system can be installed in a serial or parallel configuration along the river to increase power production [10-15].

The turbine power output ranges from 3.3 to $20 \mathrm{~kW}$ for an average plant capacity of $7.5 \mathrm{~kW}$ with an efficiency between $42 \%$ and $66 \%$ [12]. This efficiency is lower compared to the efficiency of the Kaplan turbine and that of the Archimedes turbine (efficiency in the range from $76 \%$ to $84 \%$ and from $83 \%$ to $92 \%$, respectively) [16]. However, the system yields a higher efficiency in 
comparison with a traditional undershot or overshot waterwheels, which exhibit an efficiency in the range from 35 to $40 \%$ [17].

In the literature, a limited number of studies focused on the design (component physical geometry) and manufacture of the vortex turbine. Furthermore, to the authors' knowledge, no researches based on the assessment of the influence of the wrap-around inlet on the mentioned turbine geometrical configuration have been reported. Under this scenario, this work is aiming at determining an optimal inlet channel and basin for vortex generation using Computational Fluid Dynamics (CFD) numerical models developed in Ansys Fluent software.

\section{Channel and basin configuration}

For GWVT, the inlet water flow rates used for the energy generation are conducted by a channel connected to the basin that contains the generation unit. The basin could

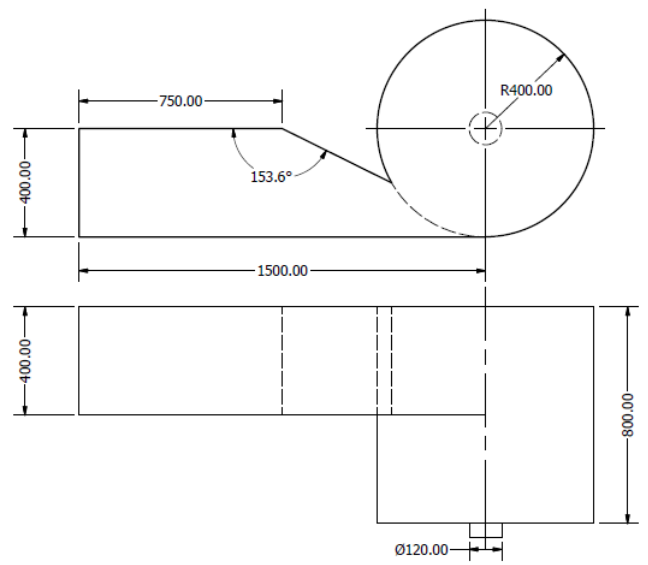

a)

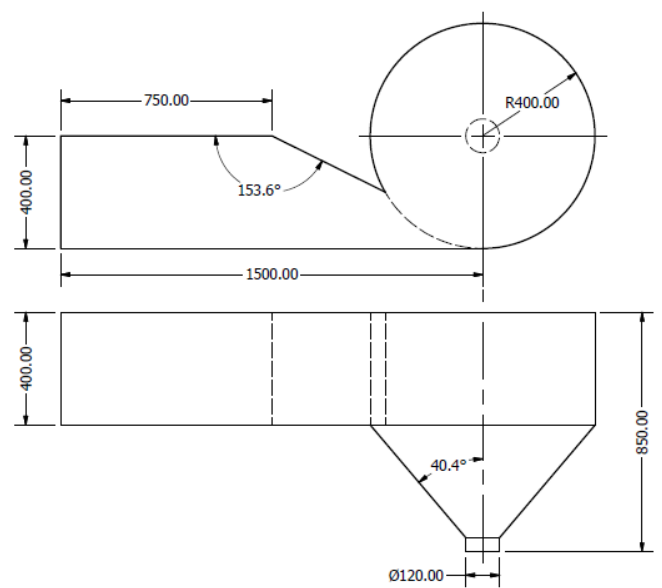

c)

Fig. 1. Geometrical configuration of the inlet channel and basin. a) Tangential inlet with cylindrical basin, b) wrap-around inlet with cylindrical basin c) tangential inlet with conical basin, d) wrap-around inlet with conical basin.

have a cylindrical or conical geometrical configuration. Therefore, four geometrical configurations that result of the combination of two inlet channel types and two basin types were investigated in order to define the model with the best performance for the generation of vortex. In this regard, several models were modelled using CAD Solidworks software. The first model used a cylindrical basin with a tangential inlet channel; in turn, the second model was based on a cylindrical basin with a wraparound inlet channel; the third model used a conical basin with a tangential inlet channel; and, finally, the latter one used a conical basin with a wrap-around inlet channel. The inlet channel had a square cross-section and was located at the upper part of the basin, uncovered at the top. The geometrical configurations and dimensions are shown in Fig. 1.

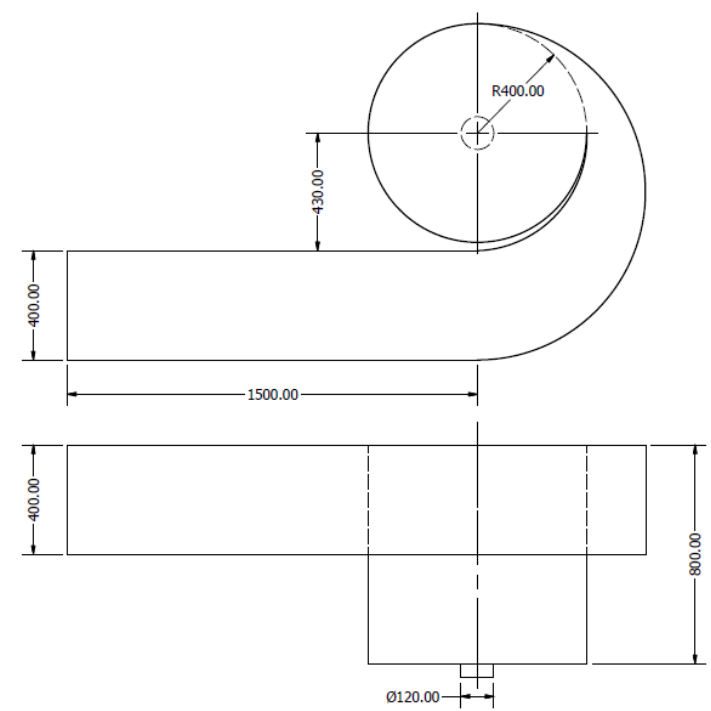

b)
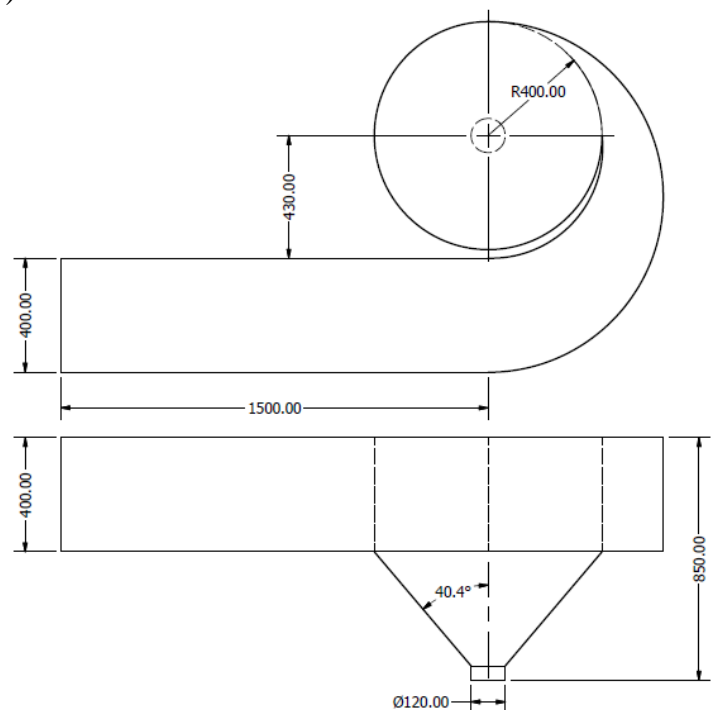

d) 
The models had an orifice at the bottom centre. For the four models, the inner diameter (D) of the basin was 800 $\mathrm{mm}$, and the diameter of the hole (d) at the bottom of the basin, $120 \mathrm{~mm}$. The d/D was taken as 0.15 . An optimum ratio $d / D$ in the range of 14\%-18\% for low and high head sites, respectively, has been claimed in cylindrical basins in the past for strong vortex formation [18-21]

The height $(\mathrm{H})$ of the cylindrical and conical basin was $800 \mathrm{~mm}$. The inlet channel length was $1500 \mathrm{~mm}$. In turn, the channel width and height were $0.5 \mathrm{H}$; therefore, theses geometrical parameters were equal to $400 \mathrm{~mm}$. For models with conical basin, the cone angle was assumed to be $40.4^{\circ}$.

\subsection{Numerical analysis}

In this study, CFD was used to simulate and compare the vortex formation in four geometrical configurations of the inlet channel and basin of a gravitational water vortex power plant. The turbine was not introduced in the analysis; therefore, its effect on the vortex formation was not considered in the numerical simulation. In theses studies, three-dimensional unsteady flow analyses were performed by considering the free surface. The Reynoldsaveraged Navier-Stoke (RANS) equations were taken as the governing equations with the $\boldsymbol{k}-\boldsymbol{\varepsilon}$ turbulence model. These equations were discretized by the finite volume method using the commercial CFD package Ansys Fluent software. The convergence criterion for the whole set of equations was $10^{-4}$ [22].

The type of analysis to be performed was of transitory nature, which allowed observing the changes in the velocity and pressure field, from the beginning of the vortex formation to its stability. Gravity, with a magnitude of $9.81 \mathrm{~m} / \mathrm{s}^{2}$, was considered in the analysis. The working fluids were water and air. The vortex

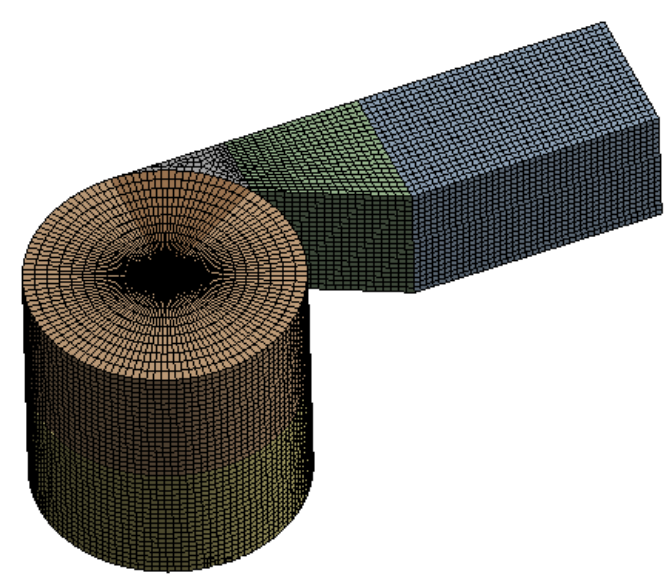

a) velocity field and height were evaluated using the referred software.

A computational grid for the four models are illustrated in Fig 2. The entire volume of each model was divided into around 14 main volumes in order to mesh the computational domain. A structured mesh was used in this study with hexahedral elements. A study of the grid independence was conducted to ensure the achievement of the solution convergence. The number of elements used in the final computational domain for the simulation of models 1, 2, 3 and 4 were 843052, 961014, 720216 and 901779 , respectively.

As boundary conditions for the whole set of models, the inlet velocity $(0.1 \mathrm{~m} / \mathrm{s})$ was given to the inlet boundary; in addition, open boundary (total pressure of $0 \mathrm{~Pa}$ for the inflow or relative static pressure of $0 \mathrm{~Pa}$ for the outflow) was considered to the outlet boundary. Furthermore, the upper surfaces of the channel and basin were set to open boundaries (relative static pressure of $0 \mathrm{~Pa}$ ), so that air could enter and exit freely; i.e., the upper surfaces of computational domain were subjected to atmospheric pressure. Moreover, the wall surface was set to the nonslip condition.

In the unsteady flow analysis, a temporary step of 0.1 seconds was used for a total simulation time of 300 seconds; time that was sufficient for the vortex of the four models to be formed and stabilized. Fig. 3 represents the changes in the output mass flow as a function of the simulation time. For the models with wrap-around inlet, the time required for the mass flow to be stabilized (maintaining a constant flow in the gravitational vortex of $16 \mathrm{~kg} /)$ was observed to be less than that for models with tangential inlet.

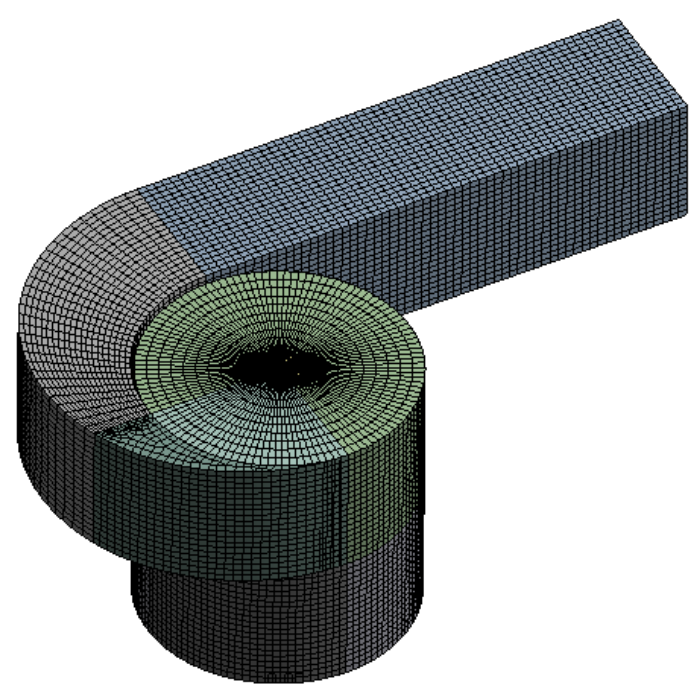

b) 

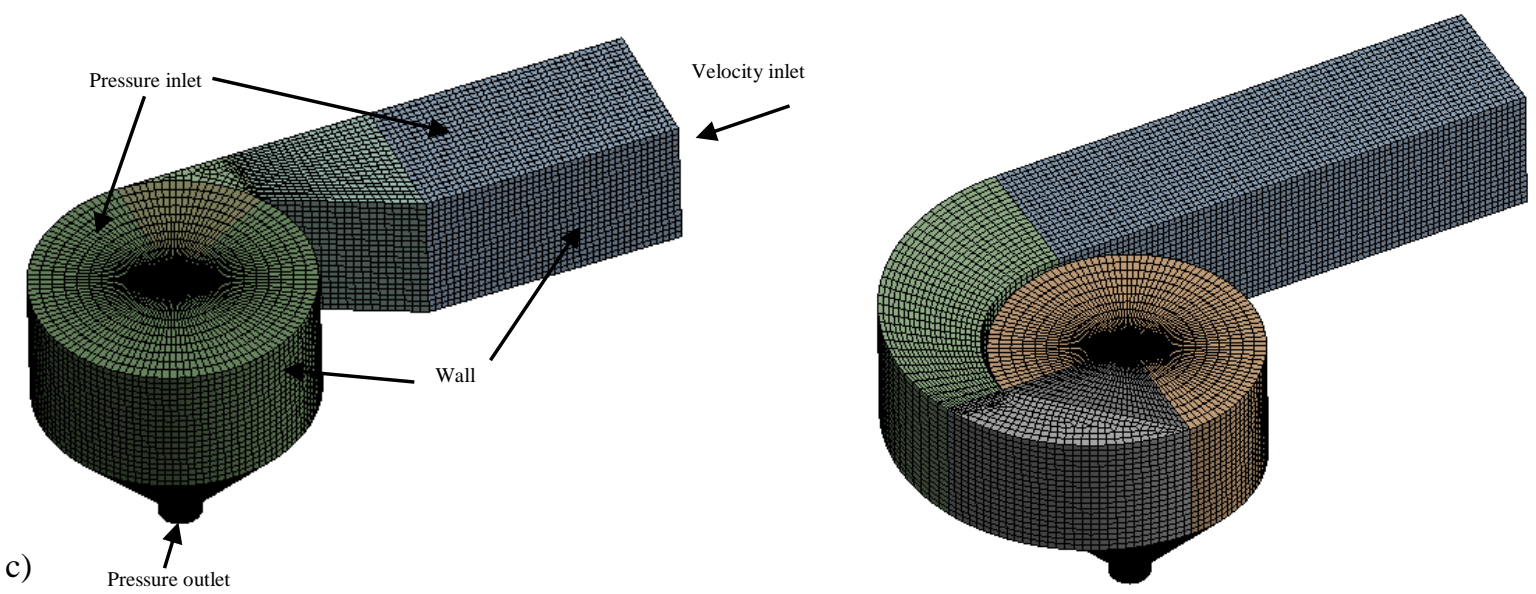

d)

Fig. 2. Computational domain of the inlet channel and basin. a) Tangential inlet with cylindrical basin, b) surrounding inlet with cylindrical basin, c) tangential inlet with conical basin, d) surrounding inlet with conical basin.

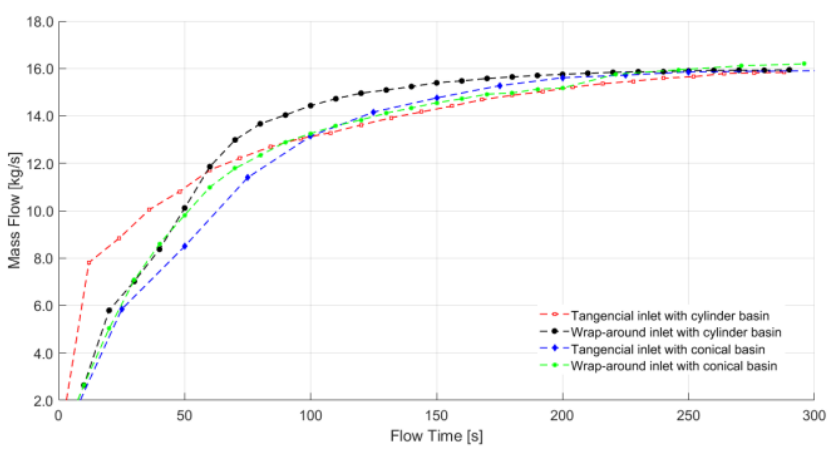

Fig. 3. Mass flow as a function of the time.

\section{Results and discussion}

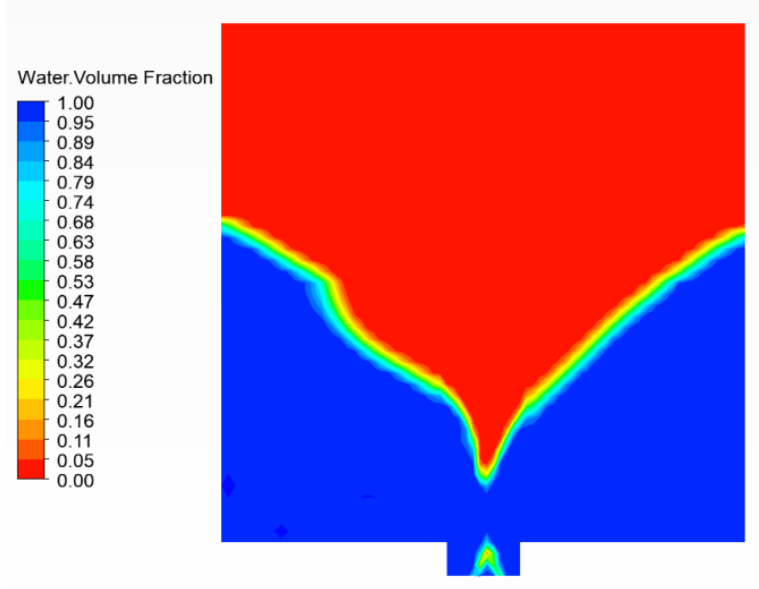

a)
It is noteworthy that depending on the design of the GWVT basin, the vortex profiles created are different. Fig. 4 shows the volume fraction of water and air at 300 s. Water in Fig. 4 is represented by the red color, while air, by the blue color. Fig. 4 illustrates the vortices, which are perfectly formed. The vortex of model 4 (i.e., the model with wrap-around inlet and conical basin) can be observed to be more symmetrical and higher than those ones obtained with the other evaluated models.

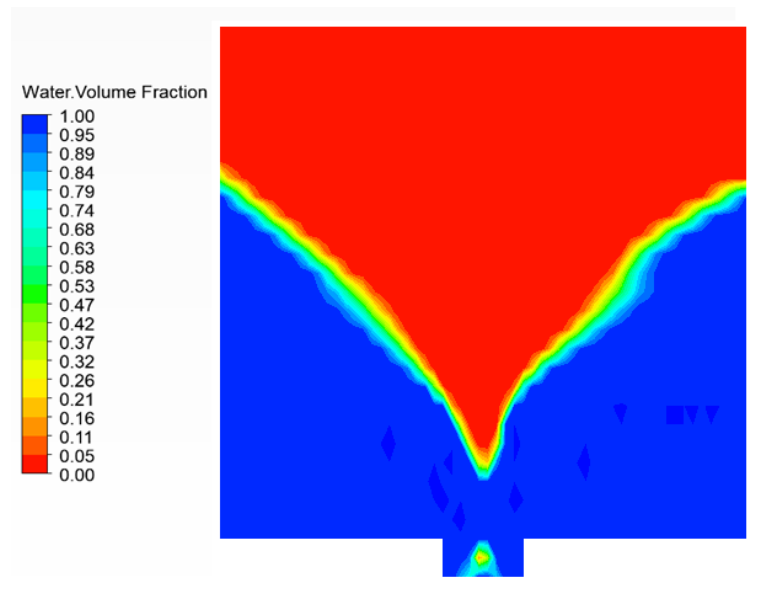

b) 

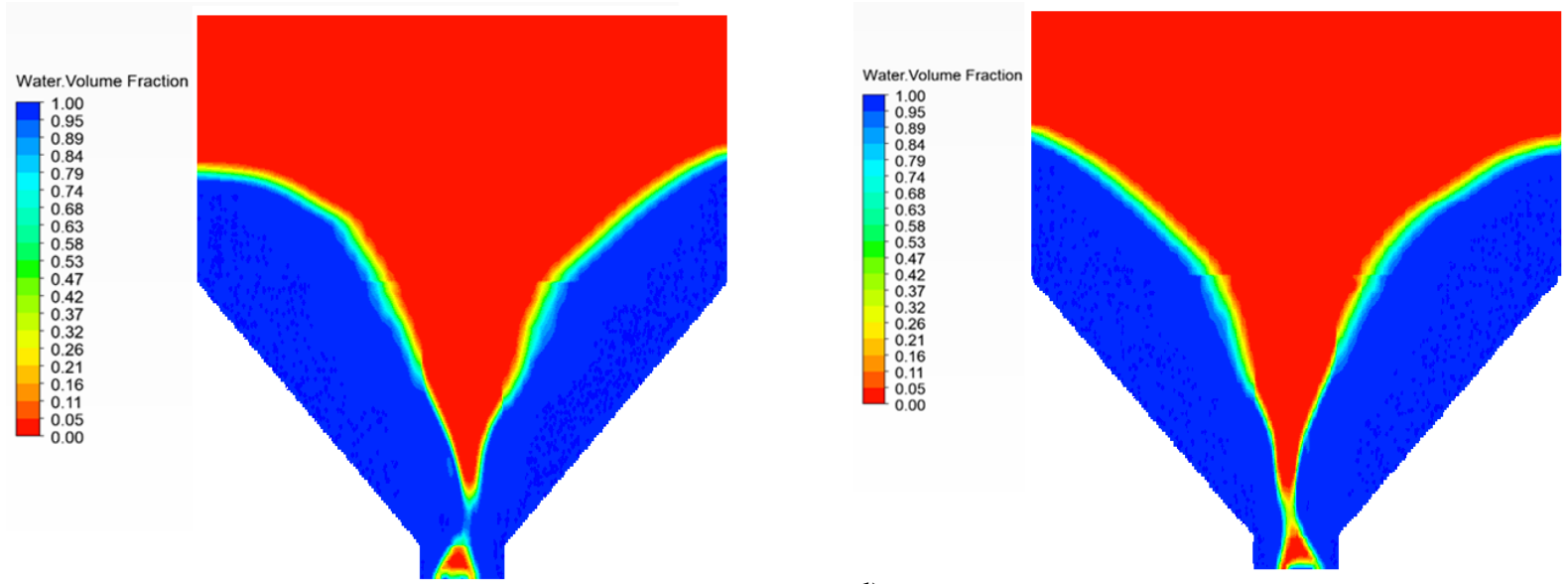

d)

c)

Fig. 4. Water volume fraction at $300 \mathrm{~s}$. a) Tangential inlet with cylindrical basin, b) wrap-around inlet with cylindrical basin, c) tangential inlet with conical basin, d) wrap-around inlet with conical basin.

Fig. 5 shows that the conical basin in both inlet geometries produces a symmetric and stable vortex. It is important to note that a symmetric vortex causes a radial force of lesser magnitude. Additionally, radial steering forces are responsible for creating moments of flexion in the shaft of the turbine, which reduce its efficiency and durability [23]

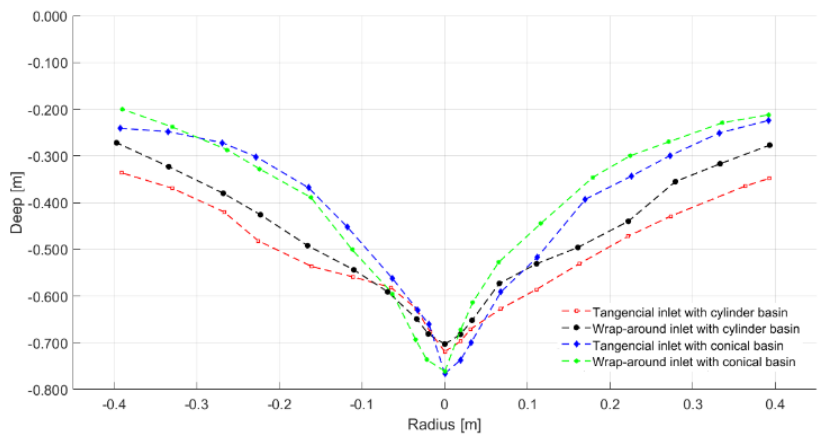

Fig. 5. Vortex profile for different basins and inlets.

The tangential velocity component is one of the most important characteristics of the vortex flow. The tangential velocity distribution along the radial direction is represented in Fig. 6. It was found that, from the radius of the vortex core, the tangential velocity increases to a maximum value, which is reached at a radius that is approximately equal to $50 \%$ of the basin radius. Furthermore, the wrap-around the inlet with conical basin configuration was observed to provide the largest values for tangential velocities of $1.55 \mathrm{~m} / \mathrm{s}$ when the radius was $0.22 \mathrm{~m}$.

In general terms, from the flow simulation, the average velocity in the conical basin was higher than that in the cylindrical basin for similar conditions of head and discharge. This can be explained as a consequence of the inflow area decrease in the conical basin. Velocity increases, thereby, maintaining a constant flow rate. From the results obtained, the same turbine should be expected to extract much more power from the conical basin than from the cylindrical one since the power output is influenced by the vortex height and the water flow rate.

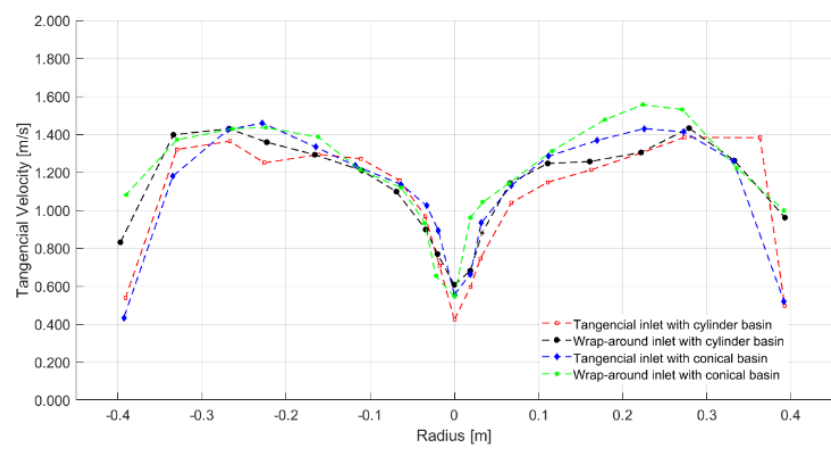

Fig. 6. Tangential velocity distribution along the radial direction for different basins and inlets.

Thus, the computational study suggests that the conical basin is much better than the cylindrical one for the provided head and discharge. It is highlighted that several researchers also conducted a number of tests on the basin $[12,15,24]$. They found that the vortex strength in the conical basin was stronger than in the cylindrical basin.

\section{Conclusion}

Gravitational water vortex power plants can be a suitable option for rural electrification. This system is an emerging technology in the context of low head hydropower plants. The channel design and basin are important parameters for effective vortex generation; therefore, CFD analysis were conducted on the inlet channel (tangential or wrap-around inlet) and the basin (cylindrical or conical) of a GWVT in order to discern the effect of the combination of geometrical configuration of these components. Four configuration with diameter and height of the basin of 0.8 $\mathrm{m}$ were modelled. The performances of the models based on the tangential velocity and the quality of the vortex produced were studied. It was found that a conical basin with an orifice at the bottom centre was the most suitable configuration to create larger kinetic energy in the vortex. 
Additionally, it was observed that model 4, defined by a wrap-around inlet and conical basin, was the most suitable basin since it provided better and more uniform velocity compared to the other models evaluated.

Furthermore, from the result analysis, it was evidenced that model 4 configuration provided the maximum tangential velocity, which is a relevant component to drive the turbine blade. This velocity was proportional to the power output. On the other hand, it is important to note that knowing the location of the highest velocity allow identifying the optimum point of a rotor installation, since a greater extraction of energy from the flow is possible at this point.

\section{Acknowledgement}

The authors gratefully acknowledge the financial support provided by the Colombia Scientific Program within the framework of the call Ecosistema Científico (Contract No. FP44842- 218-2018).

\section{References}

[1] M. Balat, "Usage of energy sources and environmental problems", Energy exploration \& exploitation (2005). Vol. 23(2), pp. 141-167.

[2] F. Zeren, and H.T. Akkuş, "The relationship between renewable energy consumption and trade openness: New evidence from emerging economies", Renewable Energy, (2020). Vol. 147, pp. 322-329.

[3] M. De Simón-Martín, Á., De la Puente-Gil, D. Borge-Diez, T. Ciria-Garcés and A. González-Martínez, "Wind energy planning for a sustainable transition to a decarbonized generation scenario based on the opportunity cost of the wind energy: Spanish Iberian Peninsula as case study", Energy Procedia, (2019). Vol. 157, pp. 1144-1163.

[4] N.F. Yah, A.N. Oumer and M.S. Idris, "Small scale hydropower as a source of renewable energy in Malaysia: A review", Renewable and Sustainable Energy Reviews, (2017). Vol 72, pp. 228-239.

[5] W. Uddin, K. Zeb, A. Haider, B. Khan, S. ul Islam, M. Ishfaq and H.J. Kim, "Current and future prospects of small hydro power in Pakistan: A survey”, Energy Strategy Reviews, (2019). Vol. 24, pp. 166-177.

[6] D. Zhou and Z.D. Deng, "Ultra-low-head hydroelectric technology: A review", Renewable and Sustainable Energy Reviews, (2017). Vol 78, pp. 23-30.

[7] N.F. Yah, A.N. Oumer, and M.S Idris, "Small scale hydropower as a source of renewable energy in Malaysia: A review", Renewable and Sustainable Energy Reviews, (2017). Vol. 72, pp. 228-239.

[8] T. Cheng, S. Lin, D. Rilling and Y. Ooi, "Numerical Analysis of Water Vortex Formation for the Water Vortex Power Plant", International Journal of Innovation, Management and Technology, (2014). Vol. 5, pp. 111-115.

[9] Zotl€oterer, Smart-energy-systems: Gravitation Water Vortex Power Plants, $2017 . \quad$ Retrieved from, http://www.zotloeterer.com/welcome/gravitation-water-vortexpower-plants/application-area/. (Accessed 16 September 2019). [10] V.J.A. Guzmán, J.A. Glasscock and F. Whitehouse, "Design and construction of an off-grid gravitational vortex hydropower plant: A case study in rural Peru", Sustainable Energy Technologies and Assessments, (2019). Vol. 35, pp. 131138.

[11] M.M. Rahman, J.H. Tan, M.T. Fadzlita and A.W.K. Muzammil, "A Review on the development of Gravitational Water Vortex Power Plant as alternative renewable energy resources", In IOP Conference Series: Materials Science and Engineering. Vol. 217, No. 1, p. 012007. IOP Publishing.

[12] A.B. Timilsina, S. Mulligan and T.R Bajracharya, "Water vortex hydropower technology: a state-of-the-art review of developmental trends", Clean Technologies and Environmental Policy, (2018). Vol. 20(8), pp. 1737-1760.

[13] R. Ullah, T.A. Cheema, A.S. Saleem, S.M. Ahmad, J.A Chattha and C.W. Park, "Preliminary experimental study on multi-stage gravitational water vortex turbine in a conical basin", Renewable Energy, (2020). Vol. 145, pp. 2516-2529.

[14] M.M. Rahman, J.H. Tan, M.T. Fadzlita and A.W.K Muzammil, "A Review on the development of Gravitational Water Vortex Power Plant as alternative renewable energy resources". In IOP Conference Series: Materials Science and Engineering (Vol. 217, No. 1, p. 012007). IOP Publishing.

[15] S. Dhakal, A.B. Timilsina, R. Dhakal, D. Fuyal, T.R. Bajracharya, H.P Pandit, A. Nagendra and A.M. Nakarmi, "Comparison of cylindrical and conical basins with optimum position of runner: Gravitational water vortex power plant", Renewable and Sustainable Energy Reviews, (2015). Vol. 48, pp. 662-669.

[16] Waters, S., Aggidis, G. A. Over 2000 years in review: Revival of the Archimedes screw from pump to turbine. Renewable and Sustainable Energy Reviews,2015, 51. pp. 497-505

[17] Quaranta, E., Fontan, S., Cavagnero, P. A. O. L. O., Revelli, R.). Efficiency of traditional water wheels. In Eproceedings of the 36th IAHR World Congress, Vol. 28. 2015, June.

[18] S. Mulligan, and P. Hull, "Design and Optimisation of a Water Vortex Hydropower Plant", Undergraduate thesis. Sligeach: Department of Civil Engineering and Construction, IT Sil. Ireland. (2010)

[19] J.A. Chattha, T.A. Cheema and N.H. Khan, "Numerical investigation of basin geometries for vortex generation in a gravitational water vortex power plant”. In 2017 8th International Renewable Energy Congress (IREC) (pp. 1-5). IEEE.

[20] N.H. Khan, T.A. Cheema, J.A. Chattha and C.W. Park, "Effective Basin-Blade Configurations of a Gravitational Water Vortex Turbine for Microhydropower Generation", Journal of Energy Engineering, (2018). 144(4), pp. 04018042.

[21] S.R. Sreerag, C.K. Raveendran and B.S. Jinshah, "Effect of outlet diameter on the performance of gravitational vortex turbine with conical basin", J. Scientific \& Engineering Research, (2016). Vol. 7(4), pp. 457-463.

[22] Y. Chen, C. Wu, B. Wang and M. Du, "Three-dimensional numerical simulation of vertical vortex at hydraulic intake", Procedia Engineering, (2012). Vol. 28, pp. 55-60.

[23] D. Thapa, A. Mishra, K.S. Sarath, "Effect of inlet geometry in the quality of vortex formed using vortex flow cannel". International Journal of Mechanical Engineering and Technology, Vol. 8. 2017.

[24] S. Dhakal, S. Nakarmi, P. Pun, A.B. Thapa and T.R. Bajracharya, "Development and testing of runner and conical basin for gravitational water vortex power plant", Journal of the Institute of Engineering, (2014). Vol. 10(1), pp. 140-148. 